\title{
POTENTIAL DRUG-DRUG INTERACTIONS IN PSYCHIATRIC PATIENTS DURING HOSPITALIZA- TION AND AT HOSPITAL DISCHARGE
}

\author{
Koraliya Todorova-Nenova ${ }^{1}$, Maria Zhelyazkova-Savova ${ }^{2}$, Silvia Gancheva ${ }^{2}$, \\ Elitsa Stoychev ${ }^{3}$ \\ 1) Department of Psychiatry and Medical Psychology, Medical University - \\ Varna \\ 2) Department of Pharmacology and Clinical Pharmacology and Therapy, Fac- \\ ulty of Medicine, Medical University - Varna \\ 3) Department of Pharmacology, Toxicology and Pharmacotherapy Faculty of \\ Pharmacy, Medical University - Varna, Bulgaria.
}

\section{ABSTRACT}

Purpose: The present study aimed to evaluate the frequency of pDDIs in male patients admitted to a universitybased intensive psychiatric unit over a twelve-month period and to assess patients' exposure to pDDIs as inpatients and potential outpatients

Material/Methods: Charts of 425 consecutive hospitalized patients with psychiatric disorders were reviewed. Potential DDIs were assessed and categorized using Lexicomp® drug interaction software. Statistical analyses were performed with IBM SPSS Statistics for Windows, Version 20.0 .

Results: A total of 1404 pDDIs (3.3 per patient) were identified for the hospitalization period. Categorized in risk rating categories $\mathrm{X}$ and $\mathrm{D}$, considered most relevant for the safety of the patients were 346 (24.64\%) of them. Among the pharmacodynamic pDDIs, most frequent were pDDIs associated with central nervous system depression, followed by QT interval prolongation.

Hospital discharge prescriptions included 631 pDDIs (1.48 per patient). Out of them, $144(22.82 \%)$ were identified in risk rating categories $\mathrm{X}$ and $\mathrm{D}$. Among the pharmacodynamic pDDIs first in frequency were pDDIs related to QT-interval prolongation, followed by pDDIs associated with central nervous system depression.

Potential DDIs that could lead to serotonin syndrome or extrapyramidal side effects were relatively infrequent during hospitalization and at discharge. No pharmacokinetic pDDIs were categorized in groups $\mathrm{X}$ and $\mathrm{D}$.

Conclusions: The study showed a higher frequency of pDDIs during the hospitalization period compared to hospital discharge with no change of the nature of the potential risks for the safety of the patients. Caution is warranted to limit the exposure of the patients to pDDIs.

Keywords: potential drug-drug interactions, psychiatric patients, discharge prescriptions,

\section{INTRODUCTION:}

A drug-drug interaction (DDI) may be defined as interference of one drug with the pharmacological activity of another, causing a quantitative or qualitative change in its effects [1]. In consequence, decreased effectiveness and/or increased toxicity may occur, resulting in the development of adverse drug reactions (ADRs), comorbid disorders, or even life-threatening conditions leading to hospitalizations or prolonging current ones [2]. The frequency and severity of DDIs are relevant to the number of medications taken by a patient and also to other factors as age, gender, comorbid conditions, etc. [3]. Polypharmacy increases the risk of DDIs, estimated by some authors as $6 \%$ in patients taking 2-4 drugs to $50 \%$ in those taking 5 drugs and nearly $100 \%$ in those taking 10 drugs [4]. On the other side good knowledge of the mechanisms and the risk factors for the occurrence of DDIs makes them predictable and their consequences avoidable or manageable. Potential DDIs are not equally relevant for clinical practice but being aware of them is a key principle of safe and effective treatment.

The present study aimed to assess the frequency of pDDIs in male patients with psychiatric disorders hospitalized in a university-based intensive psychiatric unit over a 12-month period by retrospective medical record review, including the discharge medication prescriptions. Evaluation of patients' pDDIs exposure as inpatients and potential outpatients has been carried out.

\section{MATERIALS AND METHODS:}

A retrospective chart review was conducted for 425 consecutive hospitalized male patients over a twelvemonth period to the acute unit of a university-based psychiatric clinic.

The following data were collected: age at hospital admission, length of hospital stay, psychiatric diagnoses, principal and additional if assigned, somatic comorbidity, prescribed medications during the hospital stay and at hospital discharge. 
Potential DDIs were assessed and categorized using Lexicomp® (Lexicomp, Inc., Ohio, USA) drug interaction software, an online drug information database, accessible through a subscription to UpToDate (UpToDate Inc., MA, USA), which permits identification of pDDIs and consid- ers patient treatment guidelines [5]. Each interaction outline corresponds to a risk rating category, which provides both the urgency and the nature of actions necessary to respond to an interaction. Description of the risk rating categories is provided in Table 1.

Table 1. Risk rating categories as presented by Lexicomp® for drug-drug interactions

\begin{tabular}{|c|c|l|}
\hline Risk rating & Action & \multicolumn{1}{c|}{ Description } \\
\hline X & Avoid combination & $\begin{array}{l}\text { Data demonstrate that the specified agents may interact with each other in a clini- } \\
\text { cally significant matter. The risks associated with the concomitant use of these } \\
\text { agents usually outweigh the benefits. These agents are generally considered con- } \\
\text { traindicated. }\end{array}$ \\
\hline D & $\begin{array}{l}\text { Consider therapy } \\
\text { modification }\end{array}$ & $\begin{array}{l}\text { Data demonstrate that the specified agents may interact with each other in a clini- } \\
\text { cally significant manner. A patient-specific assessment must be conducted to de- } \\
\text { termine whether the benefits of concomitant therapy outweigh the risks. Specific } \\
\text { actions must be taken in order to realize the benefits and/or minimize the toxic- } \\
\text { ity resulting from the concomitant use of the agents. These actions may include } \\
\text { aggressive monitoring, empiric dosage changes or choosing alternative agents. }\end{array}$ \\
\hline C & Monitor therapy & $\begin{array}{l}\text { Data demonstrate that the specified agents may interact with each other in a clini- } \\
\text { cally significant manner. The benefits of concomitant use of these two medica- } \\
\text { tions usually outweigh the risks. An appropriate monitoring plan should be im- } \\
\text { plemented to identify negative effects. Dosage adjustments on one or both agents } \\
\text { may be needed in a minority of patients. }\end{array}$ \\
\hline B & No action needed & $\begin{array}{l}\text { Data demonstrate that the specified agents may interact with each other, but there } \\
\text { is little to no evidence of clinical concern resulting from concomitant use. }\end{array}$ \\
\hline A & $\begin{array}{l}\text { No known } \\
\text { interaction }\end{array}$ & $\begin{array}{l}\text { Data have not demonstrated either pharmacodynamic or pharmacokinetic inter- } \\
\text { actions between the specified agents. }\end{array}$ \\
\hline
\end{tabular}

According to their mechanism, pDDIs were classified as pharmacokinetic or pharmacodynamic.

All pDDIs were analyzed with respect to the exposure of the patients to potential risks or presumed organ toxicity.

The ICD-10 diagnosis classification system was used.

Statistical analyses were performed with IBM SPSS Statistics for Windows, Version 20.0.

Approval for the study was obtained from the Ethical Committee of the Medical University of Varna.

\section{RESULTS:}

Four hundred twenty-five patients with a mean age of 41.4 (SD: \pm 13.7 ) were included in the study. All of them were admitted to the acute unit of the psychiatric clinic because of a psychiatric condition indicated for hospitalization at the time of their presentation.

Patients' primary mental and behavioral disorders diagnoses, the ICD-10 classification criteria applied, are shown in Table 2.

Table 2. Primary mental and behavioral disorders diagnoses of the patients (the ICD-10 classification criteria)

\begin{tabular}{|l|l|c|}
\hline \multicolumn{2}{|c|}{ Diagnosis } & $\begin{array}{c}\text { Number } \\
\text { of patients }\end{array}$ \\
\hline $\begin{array}{l}\text { Schizophrenia, schizotypal and delusional } \\
\text { disorders }\end{array}$ & Schizophrenia & 197 \\
\cline { 2 - 3 } Mood disorders & Acute and transient psychotic disorder & 6 \\
\hline \multirow{3}{*}{$\begin{array}{l}\text { Mental and behavioral disorders due to } \\
\text { psychoactive substance use }\end{array}$} & Bipolar affective disorder & 57 \\
\cline { 2 - 3 } & Recurrent depressive disorder & 50 \\
\cline { 2 - 3 } & Severe depressive episode & 44 \\
\cline { 2 - 3 } & Use of alcohol & 5 \\
\cline { 2 - 3 } & Uultiple drug use and use of other psychoactive & 6 \\
\hline
\end{tabular}




\begin{tabular}{|l|l|c|}
\hline \multirow{4}{*}{$\begin{array}{l}\text { Organic, including symptomatic mental } \\
\text { disorders }\end{array}$} & Vascular dementia & 3 \\
\cline { 2 - 3 } & Dementia in Alzheimer's disease & 7 \\
\cline { 2 - 3 } & $\begin{array}{l}\text { Other mental disorders due to brain damage and } \\
\text { dysfunction and to physical disease }\end{array}$ & 7 \\
\cline { 2 - 3 } & $\begin{array}{l}\text { Personality and mental disorders due to brain disease, } \\
\text { damage and dysfunction }\end{array}$ & 12 \\
\hline Mental retardation & 11 \\
\hline Disorders of adult personality and behavior & 9 \\
\hline Neurotic, stress-related and somatoform disorders & 16 \\
\hline
\end{tabular}

Thirteen of all patients had dual psychiatric diagnoses. Somatic and/or neurologic comorbidity was present in 118 patients, 27 of them with more than one comorbid condition. Length of hospital stay ranged from 3 to 60 days, with a mean of 21.7(SD: \pm 10.5 ) days.

A total of 1515 drugs (3.6 per patient) were prescribed to the patients during the hospitalization period. Discharge prescription lists contained 1107 drugs (2.6 per patient)

Hospitalization period: A total of 1404 pDDIs (3.3 per patient) were detected for the period of the hospital stay, out of them $346(24.6 \%)$ were nategorized in risk rating categories $\mathrm{X}$ or $\mathrm{D}$, which were considered most relevant to the safety of the patients and the effectiveness of the treatment. Out of all patients $405(95.3 \%)$ were exposed to at least one pDDI, and 241 patients (56.7\%) received at least one drug pair combination from risk rating category $\mathrm{X}$ or/ and D, requiring specific actions. Only 20 patients $(4.71 \%)$ had received drug combinations with no known interaction.

From the pharmacodynamic pDDIs, most frequent were pDDIs associated with central nervous system depression -547 , which affected 330 patients $(77.7 \%)$. Diazepam was involved in 348 of these pharmacodinamic pDDIs $(63.62 \%)$. Several cases of parenteral co-administration of diazepam and olanzapine were detected, which might be considered contraindicated due to the significant risk of excessive cardiovascular and central nervous system depression.

Drug pairs synergistic in causing QT- interval prolongation with the potential risk of arrhythmias were associated with 182 pDDIs affecting 157 patients (36.9\%). Amisulpride-clozapine, zuclopenthixole-risperidone, zuclopenthixole-quetiapine, ziprazidone-chlorpromazine were mainly the drug pairs involved in these pDDIs.
Drug pair combinations associated with pDDIs that could result in serotonin syndrome or extrapyramidal side effects were relatively infrequent and constituted 3\% and $2.3 \%$, respectively, of all pDDIs during the hospitalization period.

Pharmacokinetic pDDIs were detected in the prescriptions of 208 patients (48.9\%). None of them were categorized in group X or D.

At hospital discharge: Hospital discharge prescriptions included 631 pDDIs (1.5 per patient), involving 318 (74.8\%) patients. Identified in risk rating categories $\mathrm{X}$ or D were 144 of them, affecting 115 of the patients (27.1\%). Out of all patients at discharge, 51 patients $(12.1 \%)$ were exposed to at least one pDDI from category $\mathrm{X}$, and $69 \mathrm{pa}-$ tients $(16.3 \%)$, to at least one pDDI from category D. The potential risk events remained unchanged in nature. As to the pharmacodynamic pDDIs, most relevant to clinical practice at hospital discharge were 127 of them (20.1\%), associated with QT-interval prolongation affecting 116 patients $(27.3 \%)$. Second in frequency were pDDIs associated with central nervous system depression, involving 99 drug pairs $(15.7 \%)$ prescribed to 81 patients $(19.1 \%)$. In contrast to the prescriptions during the period of hospitalization, diazepam was involved in only 4 of these pharmacodynamic pDDIs.

Pharmacodynamic pDDIs associated with the risk of serotonin syndrome and extrapyramidal side effects were at a frequency similar to that of the hospitalization period.

Pharmacokinetic pDDIs were detected in the prescriptions of 93 of the patients (21.9\%). None of them were considered potentially harmful.

Table 3 data provide a comparison of the types of pDDIs and patients' exposure to them in the period of hospitalization to those at hospital discharge.

Table 3. Types of pDDIs and patients' exposure to them

\begin{tabular}{|l|l|l|l|}
\hline Index & $\begin{array}{l}\text { Hospitalization } \\
\text { period }\end{array}$ & $\begin{array}{l}\text { Period at } \\
\text { discharge }\end{array}$ & p \\
\hline pDDIs - overall number & 1404 & 631 & \\
\hline pDDIs - category X & $121(8.62 \%)$ & $69(10.94 \%)$ & NS \\
\hline pDDIs - category D & $225(16.03 \%)$ & $75(11.89 \%)$ & $? 0.01$ \\
\hline pDDIs - category C & $898(63.96 \%)$ & $471(74.64 \%)$ & $? 0.001$ \\
\hline pDDIs - category B & $136(9.69 \%)$ & $7(1.11 \%)$ & $? 0.001$ \\
\hline pDDIs - category A & $24(1.71 \%)$ & $9(1.43 \%)$ & NS \\
\hline
\end{tabular}




\begin{tabular}{|l|l|l|l|}
\hline pDDIs - categories(X + D) & $346(24.64 \%)$ & $144(22.82 \%)$ & NS \\
\hline pDDIs associated with CNS depression & $547(38.96 \%)$ & $99(15.69 \%)$ & $? 0.001$ \\
\hline pDDIs associated with QT- prolongation & $182(12.96 \%)$ & $127(20.13 \%)$ & $? 0.001$ \\
\hline pDDIs associated with serotonin syndrome & $42(2.99 \%)$ & $40(6.34 \%)$ & $? 0.01$ \\
\hline pDDIs associated with extrapyramidal symptoms & $32(2.28 \%)$ & $27(4.28 \%)$ & $? 0.05$ \\
\hline Patients with at least one pDDI - overall & $405(95.3 \%)$ & $318(74.82 \%)$ & $? 0.001$ \\
\hline Patients with at least one pDDI from category X & $86(20.24 \%)$ & $51(12.0 \%)$ & $? 0.001$ \\
\hline Patients with at least one pDDI from category D & $180(42.35 \%)$ & $69(16.24 \%)$ & $? 0.001$ \\
\hline Patients with at least one pDDI from category X and/or D & $241(56.71 \%)$ & $115(27.06 \%)$ & $? 0.001$ \\
\hline Patients with at least one pDDI associated with CNS sedation & $330(77.65 \%)$ & $81(19.06 \%)$ & $? 0.001$ \\
\hline Patients with at least one pDDI associated with QT- prolongation & $157(36.94 \%)$ & $116(27.29 \%)$ & $? 0.001$ \\
\hline
\end{tabular}

\section{DISCUSSION:}

This was a retrospective study with an aim to assess the frequency and nature of pDDIs associated with the pharmacotherapy of psychiatric disorders both in hospital and outpatient settings. Patients with psychiatric disorders are at particular risk for pDDIs because of the usual practice of symptom-based prescribing, longer hospital stays and multiple prescribers, and medical, including psychiatric, comorbidity. Potential DDIs are the most common cause of unexpected side effects, contribute significantly to longer hospital stays, treatment failures, and subsequent healthcare costs $[6,7]$.

A high rate of pDDIs was detected in our patient sample for the period of the hospital stay. Vasudev and Harrison (2008) reported results very close to our data in a study among hospitalized elderly psychiatric patients in Great Britain [8]. Other studies among hospitalized psychiatric patients in Pakistan and Mexico demonstrated a lower frequency of pDDIs than that in our study $[9,10]$.

The incidence of the pDDIs for our sample of patients at discharge was lower than that found for the period of the hospitalization. Similar data was published in a study among a mixed Turkish population of inpatients and outpatients with schizophrenia and schizoaffective disorder [11].

A number of factors may account for the differences in the reported data, with one of the most essential being the different databases for the assessment of pDDIs used in the studies. Vasudev and Harrison (2008) challenged this issue by discussing the concordance of two well-referenced databases they had used [8]. More recent studies also suggest increasing sensitivity related to the identification of pDDIs by combining two or more DDI-related software programs because of the much variation in their potentiality for clinical relevance $[12,13,14,15]$. Other factors that may influence the incidence rate of pDDIs are patients' age, polypharmacy, long hospital stay, the medical condition under treatment, etc. $[8,16]$. The higher prevalence of pDDIs for the psychiatric inpatients in our study may be partly due to the male sample, the acute setting of the patient unit, and the mode of prescribing associated with psychiatric emergencies. These factors may, in part, account for the most prevalent type of pharmacodynamic pDDIs during the hospitalization period in our study consisting of drug pair combinations synergistic in their CNS sedative effect. Such effects may include but are not limited to ataxia, confusion, drowsiness, respiratory depression, and weakness. It is advised to carefully monitor patients whenever two or more CNS depressants are concomitantly used [17]. While the additive sedative effect was significantly more associated with the hospital stay than the discharge period, the risk of QT prolongation was not significantly associated with the clinical setting. The pharmacodynamic pDDIs associated with a risk of cardiac rhythm complications due to QT-interval prolongation were most relevant to clinical practice for the period at discharge, with their rate almost unchanged for the hospitalization period. The potential of prolonged QTc arouses concern in clinical practice, as it can be followed by life-threatening polymorphic ventricular tachyarrhythmia called torsade de pointes (TdP) [18]. Psychotropic drugs are commonly associated with such kind of pDDIs, which are usually categorized in risk rating categories X or D. It should be noted, however, that druginduced QT prolongation and/or TdP usually occur in patients with underlying risk, i.e. age over 65 years, pre-existing cardiovascular disease, bradycardia, female sex, hypokalemia, hypomagnesemia, high therapeutic or toxic serum concentration of the prescribed drug, often in the setting of polypharmacy or the simultaneous administration of other drugs that delay repolarization or interfere with drug metabolism [18, 19]. ECG monitoring is essential to control the risk of arrhythmia, and it is recommended that the concomitant use of medications known to prolong the QT interval should be avoided in vulnerable patients $[18,19,20]$.

The prevalence rate for pharmacokinetic pDDIs in our study was lower than that of the pharmacodynamic type. The two major types of pharmacokinetically mediated pDDIs were identified in our study: those mediated by cytochrome P450 (CYP) enzymes and those mediated by transport proteins resulting in decreased/increased serum concentration of the involved medications. None of the detected pharmacokinetic pDDIs were of $\mathrm{X}$ or D risk rating. Carbamazepine, oxcarbazepine, paroxetine, fluoxetine, duloxetine, haloperidol in drug pairs with diazepam, valproic acid, aripiprazole, and metoprolol were most frequently involved in these types of pDDIs. Still, 
usually, the studies focus on CYP-based pDDIs, one of the reasons maybe being the not very clear mechanisms of the pDDIs mediated by transport proteins [21].

\section{CONCLUSIONS:}

The incidence of pDDIs was found to be higher in our patient sample in the period of the hospitalization compared to hospital discharge. Although it has been set up that pDDIs far outnumber those which lead to clinically relevant ADRs, analysis has shown that the real size of the adversely affected patients is nevertheless large enough. Together with the careful clinical, physiological and biochemical monitoring of the psychiatric patients, it is essential to consider the pharmacological features of the administered drugs and select those with the least propensity to interact.

\section{REFERENCES:}

1. Flynn E. Drug-drug interactions. In: xPharm: The Comprehensive Pharmacology Reference. Editors: Enna SJ, Bylund DB. Elsevier. 2007., pp.13. [Crossref]

2. Kapadohos T, Angelopoulos E, Vasileiadis I, Nanas S, Kotanidou A, Karabinis A, et al. Determinants of prolonged intensive care unit stay in patients after cardiac surgery: A prospective observational study. $J$ Thorac Dis. 2017 Jan;9(1):70-79. [PubMed]

3. Moura CS, Acurcio FA, Belo NO. Drug-drug interactions associated with length of stay and cost of hospitalization. J Pharm Pharm Sci. 2009; 12(3):266-72. [PubMed]

4. Patel PS, Rana DA, Suthar JV, Malhotra SD, Patel VJ. A study of potential adverse drug-drug interactions among prescribed drugs in medicine outpatient department of a tertiary care teaching hospital. J Basic Clin Pharm. 2014 Mar;5(2):44-8. [PubMed]

5. Lexicomp ${ }^{\circledR}$ Drug Interactions UpToDate.

6. Lucca JM, Ramesh M, Ram D, Kishor M. Incidence and predictors of adverse drug reactions caused by drug-drug interactions in psychiatric patients: An empirical study. Trop J Med Res. 2016 Jan-Jun;19(1):29-35.

7. Sandson NB, Armstrong SC, Cozza KL. Med-Psych drug-drug interactions update: an overview of psychotropic drug-drug interactions. Psychosomatics. 2005 Sep-Oct;46(5): 464-94. [PubMed]

8. Vasudev A, Harrison R. Prescribing safely in elderly psychiatric wards: survey of possible drug interactions. Psychiatric Bulletin. 2008 Nov;32(11):417-8. [Crossref]

9. Ismail M, Iqbal Z, Khattak MB, Javaid A, Khan MI, Khan TM, et al.
Potential drug-drug interactions in psychiatric ward of a tertiary care hospital: prevalence, levels and association with risk factors. Trop J Pharm Res. 2012 Apr;11(2):289-95. [Crossref]

10. Ocaña-Zurita MC, JuárezRojop IE, Genis A, Tovilla-Zárate CA, González-Castro TB, Lilia LópezNarváez M, et al. Potential drug-drug interaction in Mexican patients with schizophrenia. Int J Psychiatry Clin Pract. 2016 Nov;20(4):249-53. [PubMed]

11. Sengul MCB, Karadag F, Sengul C, Karakulah K, Kalkanci O, Herken H. Risk of psychotropic drug interactions in real world settings: A pilot study in patients with schizophrenia and schizoaffective disorder. Klinik Psikofarmakol Bulteni. 2014; 24(3):235-247. [Crossref]

12. Bertoli R, Bissig M, Caronzolo D, Odorico M, Pons M, Bernasconi E. Assessment of potential drug-drug interactions at hospital discharge. Swiss Med Wkly. 2010 Jul 15;140:w13043. [PubMed]

13. Hammar T, Lidström B, Petersson G, Gustafson Y, Eiermann B. Potential drug-related problems detected by electronic expert support system: physicians' views on clinical relevance. Int J Clin Pharm. 2015 Oct; 37(5):941-8. [PubMed]

14. Sancar M, $\mathrm{Ka}^{\mathrm{o}}$ ik A, Okuyan B, Batuhan S, Izzettin FV. Determination of Potential Drug-Drug Interactions Using Various Software Programs in a Community Pharmacy Setting. Turk $J$ Pharm Sci. 2019 Mar;16(1):14-19. [PubMed]

15. Gonzaga de Andrade Santos TN, Mendonça da Cruz Macieira G, Cardoso Sodré Alves BM, Onozato T,
Cunha Cardoso G, Ferreira Nascimento MT, et al. Prevalence of clinically manifested drug interactions in hospitalized patients: A systematic review and meta-analysis. PLoS One. $2020 \mathrm{Jul} 1 ; 15(7)$ : e0235353. [PubMed]

16. Murtaza G, Khan MY, Azhar S, Khan SA, Khan TM. Assessment of potential drug-drug interactions and its associated factors in the hospitalized cardiac patients. Saudi Pharm J. 2016 Mar;24(2):220-5. [PubMed]

17. Worthley LI. Clinical Toxicology: Part I. Diagnosis and Management of Common Drug Overdosage. Crit Care Resusc. 2002 Sep;4(3):192215. [PubMed]

18. Wenzel-Seifert K, Wittmann M, Haen E. QTc prolongation by psychotropic drugs and the risk of Torsade de Pointes. Dtsch Arztebl Int. 2011 Oct;108(41):687-93. [PubMed]

19. Chung AK, Chua SE. Effects on prolongation of Bazett's corrected QT interval of seven second-generation antipsychotics in the treatment of schizophrenia: A meta-analysis. $J$ Psychopharmacol. 2011 May;25(5): 646-66. [PubMed]

20. Girardin FR, Gex-Fabry M, Berney P, Shah D, Gaspoz JM, Dayer P. Drug-induced long QT in adult psychiatric inpatients: The 5-year cross-sectional ECG screening outcome in psychiatry study. Am J Psychiatry. 2013 Dec;170(12):1468-76. [PubMed]

21. Davies SJC, Eayrs S, Pratt P, Lennard MS. Potential for drug interactions involving cytochromes $\mathrm{P} 450$ 2D6 and 3A4 on general adult psychiatric and functional elderly psychiatric wards. Br J Clin Pharmacol. 2004 Apr;57(4):464-72. [PubMed] 
Please cite this article as: Todorova-Nenova K, Zhelyazkova-Savova M, Gancheva S, Stoychev E. Potential drug-drug interactions in psychiatric patients during hospitalization and at hospital discharge. J of IMAB. 2022 Jan-Mar;28(1):42234228. DOI: https://doi.org/10.5272/jimab.2022281.4223

Received: 02/06/2021; Published online: 09/02/2022

(c) $(0)$

Address for correspondence:

Koraliya Todorova-Nenova

Department of Psychiatry and Medical Psychology, Medical University - Varna, 55 Marin Drinov St, 9002 Varna, Bulgaria.

E-mail: koralia.todorova@yahoo.com 